\title{
Extracolonic polyposis in familial adenomatous polyposis: so near and yet so far
}

\author{
A D Spigelman
}

\section{There is a need to develop effective preventative and/or curative strategies for duodenal polyposis in patients with familial adenomatous polyposis}

E xtracolonic polyps in familial adenomatous polyposis (FAP) were described in the stomach by Hauser in 1895 and in the duodenum by Funkenstein in 1904. ${ }^{1}$ These findings postdate the first description of colonic lesions consistent with polyposis, described by Menzel in 1721, although this case is probably a description of inflammatory polyps. ${ }^{1}$ The first case of adenomatous polyposis may have been recorded by Corvisart in $1847 .{ }^{1}$ However, the first definite accounts of the disease were given by Chargelaigue in 1859 in a 16 year old girl and a 21 year old man. ${ }^{1}$ While polyposis has thus been reasonably well described for hundreds of years and the coexistence of extracolonic polyps in this syndrome has been known for over 100 years, it was not until 1987 that the name familial polyposis coli was abandoned in order to reflect the disparate manifestations of this syndrome throughout the body. ${ }^{2}$

There were huge differences reported across the world in the observed proportion of polyposis patients who were affected by duodenal polyposis in the 1970s and 1980s. ${ }^{1}$ Conveniently divided into reports emanating from either Japan or elsewhere, those from Japan found that $96 \%$ of polyposis patients had duodenal polyposis as well as colonic polyposis compared with $45 \%$ of polyposis patients from elsewhere. That more than double the proportion of FAP patients studied in Japan were found to have duodenal polyposis compared with those studied elsewhere was explained away by differences in either the genetic composition of the different populations or by relating this to the observed differences in rates of gastric polyps and carcinomas between Japanese and other populations. Further scrutiny reveals that most of the papers reporting low rates of duodenal polyposis were, in fact, retro- spective studies. The Japanese claims of a near universal occurrence of duodenal polyposis in FAP were subsequently substantiated in a series of prospective studies from elsewhere reported from $1989 .^{34}$ Indeed, two institutions from either side of the Atlantic proved the greater accuracy of the prospective approach by publishing both retrospective and prospective studies with findings akin to the earlier studies from elsewhere in the retrospective work and to the Japanese studies in the prospective work. ${ }^{34}$

Having acknowledged the true scale of the problem, researchers worldwide turned to the challenge of determining the frequency of the problem and its relationship to the severity of the problem, as reflected by an excess rate for duodenal carcinoma in the FAP population. ${ }^{5}$ This was followed by decade long attempts to determine the natural history of duodenal polyposis ${ }^{6-8}$ together with persisting attempts to improve our understanding of the genesis of duodenal polyposis. ${ }^{\text {Th }}$ occurred at the same time as investigators sought to prevent the onset of duodenal cancer by a range of prophylactic measures, which have had drug, endoscopic, or surgical components, ${ }^{15-8}$ with the promise of gene therapy to come. ${ }^{10-12}$ Underpinning these attempts to improve outcome was the development of the duodenal staging system now used by several groups. ${ }^{6-8}$ Despite being the subject of some cynicism initially, the staging system described appears to be useful in determining the frequency of endoscopic examination of the upper gastrointestinal tract as well as in delineating the core group of patients at very high risk for duodenal cancer and for whom preventative measures are most urgent.

Those who maintain an interest in the arcane world of duodenal polyposis in patients with familial adenomatous polyposis will note the great progress that has been made over the past 15 years, despite the relatively slow start from the time extracolonic polyposis was first described over 100 years ago. Having accepted that a problem exists and having defined the scale of that problem and the existence of a very high risk group, the remaining challenges for researchers in this area are clear. They are to develop effective preventative and/or curative strategies. If the tenacity shown by Steffen Bulow and colleagues, ${ }^{8}$ in this issue of Gut, in coordinating a multinational study over many years can be replicated in the search for these twin goals, then their achievement is, hopefully, within reach [ see page 381].

Gut 2004;53:322.

doi: 10.1136/gut.2003.032227

Correspondence to: A D Spigelman, Surgical Science, Faculty of Health, University of Newcastle, Director, Hunter Family Cancer Service, Director, Cancer Services and Director, Clinical Governance Unit, Hunter Area Health' Service, New South Wales, Australia; allan.spigelman@newcastle.edu.au

\section{REFERENCES}

1 Phillips RKS, Spigelman AD, Thomson JPS, eds. Familial Adenomatous Polyposis and Other Polyposis Syndromes. London: Edward Arnold, 1994.

2 Thomson JPS. Familial adenomatous polyposis. BMJ 1987;295:1568.

3 Spigelman AD, Williams $C B$, Talbot IC, et al. Upper gastrointestinal cancer in patients with familial adenomatous polyposis. Lancet 1989;ii:783-5.

4 Church JM, McGannon E, Hull-Boiner S, et al. Gastroduodenal polyps in patients with familial adenomatous polyposis. Dis Colon Rectum 1992;35:1170-3.

5 Spigelman AD. Familial adenomatous polyposis and the upper gastrointestinal tract. Semin Colon Rectal Surg 1995;6:26-8.

6 Groves CJ, Saunders BP, Spigelman AD, et al. Duodenal cancer in patients with familial adenomatous polyposis (FAP): results of a 10 year

7 prospective study. Gut 2002;50:636-41. Bjork J, et al. Worldwide survey among polyposis registries of surgical management of severe duodenal adenomatosis in familial adenomatous polyposis. Br J Surg 2003;90:705-10.

8 Bulow S, Björk J, Christensen IJ, et al. Duodenal adenomatosis in familial adenomatous polyposis. Gut 2004;53:381-6.

9 Spigelman AD. Studies of the foregut in patients with familial adenomatous polyposis (FAP): Clinical problem, management and pathogenesis, MD thesis. Sydney: University of Sydney, 1996.

10 Hargest R, Eldin A, Willimason R. Gene therapy for familial adenomatous polyposis. Prolonged expression of the adenomatous polyposis coli gene after lipofection into mouse colon in vivo. Adv Exp Med Biol 1998;451:385-91.

11 His LC, Angerman-Stewart J, Eling TE. Introduction of full length APC modulates cyclooxygenase- 2 expression in HT-29 human colorectal carcinoma cells at the translational level. Carcinogenesis 1999;20:2045-49.

12 Bright-Thomas RM, Agrawal A, Hargest R. Preclinical studies of gene transfer for the treatment of desmoid disease in familial adenomatous polyposis. $\mathrm{Br} J$ Surg 2002;89:1563-9. 